\title{
Avaliação de poluentes aéreos em instalações de creche e terminação de suínos
}

\author{
Evaluation of aerial pollutants in nursery and finishing swine housing
}

\author{
Carlos Augusto de Paiva Sampaio ${ }^{I}$ Irenilza de Alencar Nääs ${ }^{I I}$ \\ Marta dos Santos Baracho ${ }^{\mathrm{II}}$ Douglas D’alessandro Salgado ${ }^{\mathrm{II}}$
}

\section{RESUMO}

Esta pesquisa foi desenvolvida em duas instalações para suínos nas fases de creche e terminação, em duas salas cada, em granjas localizadas no município de Salto, SP, com os objetivos de avaliar a concentração de amônia e poeira e a presença de fungos, além de estimar os riscos de exposição ocupacional a esses agentes ambientais. As avaliações foram realizadas conforme preceituam as normas $\mathrm{NR}-15$, NIOSH e ACGIH. Os resultados indicaram diferença significativa nas concentrações de amônia em relação aos horários, às instalações e aos períodos do dia. Estes também indicam negligência para a questão da ventilação sanitária nas instalações de creche, com conseqüentes teores mais altos de amônia, e que estes estão vinculados à circulação de ar no interior das instalações, ao manejo dos dejetos e da cortina, à tipologia da construção e às condições de clima local, além da lotação e da densidade de suínos. A concentração de poeira total foi mais alta nos prédios de creche $\left(0,84-9,16 \mathrm{mg} \mathrm{m}^{-3}\right)$ do que nos de terminação $\left(0,84-3,34 \mathrm{mg} \mathrm{m}^{-3}\right)$, enquanto que a poeira respirável foi mais alta na creche, ficando inferior a $3,67 \mathrm{mg} \mathrm{m}^{-3}$ e dentro dos limites de insalubridade para o trabalhador. Foram encontrados fungos do gênero Aspergillus, Penicillium e Neurospora em suspensão no ambiente interno das instalações estudadas.

Palavras-chave: amônia, fatores ambientais, fungo, poeira, suíno.

\section{ABSTRACT}

This research was developed in two swine housings in the phases of nursery and finishing: in two pens each, in two farms located at Salto County, SP, with the objective to evaluate ammonia and concentrations, and fungi presence besides estimating the occupational risk of exposure to these environmental agents. The evaluations were done according to recommended by the norms NR-15, NIOSH e ACGIH. Results indicated significant difference in ammonia concentration in relation to the hour, the housing and to the day period. They also indicate negligence to sanitary ventilation matter in nursery housing with consequent higher level of ammonia; which are linked to the air circulation inside housing, the manure and curtain management, housing typology, and to local climate conditions; besides swine crowd and density. Total dust concentration was higher in nursery buildings $\left(0.84-9.16 \mathrm{mg}^{-3} \mathrm{~m}^{-3}\right)$ than in finishing $\left(0.84-3.34 \mathrm{mg} \mathrm{m}^{-3}\right)$, while inhale dust was higher in the nursery, however lower than $3.67 \mathrm{mg} \mathrm{m}^{-3}$, and within the labor welfare limits. There were found fungi from genus Aspergillus, Penicillium and Neurospora in suspension in the internal environmental of the studied housings.

Key words: ammonia, dust, environmental factors, fungi, swine.

\section{INTRODUÇÃO}

Nas atividades agropecuárias, os riscos de enfermidades por agentes físicos, químicos e biológicos estão sempre presentes. A amônia $\left(\mathrm{NH}_{3}\right)$ é um gás associado à redução do apetite e à irritação nas mucosas dos suínos, além de causar problemas respiratórios e letalidade aos trabalhadores. A exposição a 50ppm reduz o desempenho; a 100ppm leva a espirros e perda de apetite e, quando superior a 300ppm, pode levar a convulsões (BARKER et al., 2002). Uma alternativa de redução de amônia em instalações fechadas para suínos, usando a aspersão de uma mistura de água e ácido sulfúrico nos dejetos, foi estudada por JENSEN (2002), que manteve o $\mathrm{pH}$ dos dejetos em cerca de 5-6, reduzindo o teor de $\mathrm{NH}_{3}$ a concentrações abaixo de 5 ppm e com incrementos de até $12 \%$ no ganho de peso

IDepartamento de Engenharia Rural, Centro de Ciências Agroveterinárias, Universidade do Estado de Santa Catarina (UDESC), Lages, SC, Brasil. E-mail: a2caps@cav.udesc.br. *Autor para correspondência.

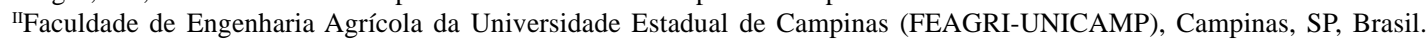


dos animais, reduzindo o risco laboral aos tratadores. A CIGR (1994), baseado em estudos específicos, recomenda a concentração máxima de 20ppm no nível dos animais. No Brasil, a NR15 (1978) regula exposições de trabalhadores a agentes agressivos especificando que a concentração média de $\mathrm{NH}_{3}$ durante a jornada de trabalho diária de 8 horas deve ser no máximo de 20ppm, não devendo exceder 30ppm. A exposição à concentração acima de $6 \mathrm{ppm}$ leva a irritação nas mucosas, a 400ppm leva à irritação nas vias aéreas superiores, podendo ser letal quando atinge 10.000ppm (BARKER et al., 2002).

Poeiras são partículas sólidas suspensas no ar, que podem ser de origem animal (pêlo, pele, couro), vegetal (ração de milho e de soja), mineral (sílica, amianto, carvão) e sintética (fibras de plástico). A ACGIH (2001) classifica as poeiras em inaláveis, com diâmetro entre $0<\phi<100 \mu \mathrm{m}$, torácicas, entre $0<\phi<25 \mu \mathrm{m}$, respiráveis, entre $0<\phi<10 \mu \mathrm{m}$, e poeira total, que não depende do tamanho das partículas. No Brasil, não existem normas específicas para poeira, como as existentes em instalações para animais; entretanto, a ACGIH (2001) e o NIOSH (1994) propõem os limites de 10 e $15 \mathrm{mg} \mathrm{m}^{-3}$ e de 3 e $5 \mathrm{mg} \mathrm{m}^{-3}$ para as frações inalável e respirável, respectivamente, para o bem-estar humano. Foi verificado por GUINGAND (1999), em estudos dentro de instalações de tipologia fechada, com renovação do ar limitada (utilizadas em países de clima frio), que a concentração de poeira total foi maior na creche $\left(6,3 \mathrm{mg} \mathrm{m}^{-3}\right)$ do que na terminação $\left(3,7 \mathrm{mg} \mathrm{m}^{-3}\right)$, resultado devido à densidade populacional, à idade e à atividade dos animais, sendo que, no inverno, a concentração foi superior à do verão; concluindo também que a concentração de poeira varia com a hora do dia e em função do tipo de ventilação, de piso e da alimentação. Avaliando a amônia e as poeiras em creche e terminação de suínos de região tropical, CHANG et al. (2001) encontraram que a concentração de $\mathrm{NH}_{3}$ foi maior nos galpões de terminação, embora a variabilidade das medidas tenha sido alta. Na creche, os autores concluíram que a concentração de poeira não foi somente mais alta, mas havia excessiva contaminação com bactérias e endotoxinas.

Fungos são agentes biológicos com significativo potencial para produzir alergia e doenças pulmonares. Os fungos do gênero Aspergillus são os principais microorganismos existentes em instalações para animais (PICKRELL, 1991). No Brasil, são poucas as pesquisas nessa área, embora as condições locais de alojamento sejam necessárias para que haja conformidade com exigências internacionais, quando tange aos exportadores.

Os objetivos deste trabalho foram avaliar a concentração de amônia ( $\mathrm{NH}_{3}$ ), de poeira total, de poeira respirável e de fungos, bem como estimar os riscos da exposição ocupacional a estes agentes em duas granjas com instalações de creche e terminação de suínos.

\section{MATERIAL E MÉTODOS}

Este trabalho foi realizado em duas granjas de produção de suínos denominadas de G1 e G2, localizadas no município de Salto, SP (latitude de $23^{\circ} 12^{\prime} 10^{\prime \prime}$ Sul e longitude $47^{\circ} 17^{\prime} 35^{\prime}$ ' Oeste e altitude média de 521m), correspondendo a quatro instalações: duas para a fase de creche e duas para a fase de terminação, nos períodos de verão e inverno de 2003. O clima predominante da região, de acordo com KÖPPEN, é Cwa: quente, temperado chuvoso, com estação seca no inverno e verão quente. A região possui temperatura média anual de $26^{\circ} \mathrm{C}$, com ventos predominantes da direção noroeste. $\mathrm{O}$ entorno das instalações era formado basicamente por grama, com árvores isoladas e o controle térmico e higiênico do ambiente aéreo era realizado por ventilação natural, manejo das cortinas e uso de lanternim.

A granja 1 (G1) possuía um padrão manual de arraçoamento na creche e na terminação nos horários da 7h15min, 9h00min, 10h30min, 12h00min e 15h00min, com a ração sendo colocada no comedouro em quantidade pré-determinada e umedecida em seguida e no último trato, às $16 \mathrm{~h} 30 \mathrm{~min}$, na forma seca. A granja 2 (G2) possuía um padrão manual de arraçoamento, sendo que, na creche, era realizado nos mesmo horários e no mesmo trato da granja 1 (G1) e, na terminação, era realizado nos horários das 7h15min, 10h00min e 12h30min, com a oferta da ração em quantidade prédeterminada e umedecida, em seguida sendo oferecida seca no último trato, às 16 h00min.

\section{Características das instalações}

As instalações de creche possuíam orientação leste-oeste, paredes de alvenaria e piso cimentado. A G1 tinha pé-direito no beiral de 2,30m, telhado de duas águas com lanternim e cobertura de telhas de fibrocimento, beiral de $0,85 \mathrm{~m}$, tendo quatro salas com área de piso de $173 \mathrm{~m}^{2}\left(0,48 \mathrm{~m}^{2}\right.$ animal $\left.{ }^{-1}\right)$, volume interno médio de $404 \mathrm{~m}^{3}$, fechamento lateral de alvenaria com $1,00 \mathrm{~m}$ de altura e uso de cortina para controle ambiental, sendo a limpeza feita diariamente pela manhã, com raspagem e lavagem eventual do piso, prioritariamente na entrada de novo lote. Nos dias de avaliação, não houve lavagem do piso; entretanto, a raspagem foi realizada diariamente na tarde. A cortina era manejada no inverno, objetivando o aquecimento à noite, e, pela manhã, as salas ficavam totalmente abertas. A sala alojava 360 suínos (fêmea Landrace $\mathrm{x}$ Large White e macho Pic), sendo que, no verão, os 
leitões possuíam peso médio de 15,20kg, com 31,62kg $\mathrm{m}^{-2}$ de piso e $13,51 \mathrm{~kg} \mathrm{~m}^{-3}$ de ar interno e, no inverno, $17,70 \mathrm{~kg}$, com $38,39 \mathrm{~kg} \mathrm{~m}^{-2}$ de piso e $15,29 \mathrm{~kg} \mathrm{~m}^{-3}$ de ar interno.

A granja 2 (G2) possuía pé-direito no beiral de 2,35m, telhado de duas águas com lanternim e cobertura de telhas de barro, beiral de $0,35 \mathrm{~m}$, sendo formada por três salas com área de piso de $61,25 \mathrm{~m}^{2}$ $\left(0,36 \mathrm{~m}^{2}\right.$ animal $\left.^{-1}\right)$ semi-ripado, volume interno de $144 \mathrm{~m}^{3}$, fechamento lateral de alvenaria com $1,55 \mathrm{~m}$ e cortina para controle ambiental, sendo a limpeza feita diariamente pela manhã com raspagem e lavagem do piso, correspondendo às baias e à fossa. A sala utilizada para as medidas alojava 140 leitões (fêmea Camborough $^{\circledR}$ e macho AgPic ${ }^{\circledR}$ ) e, no verão, os suínos tinham peso médio de 22,73kg, com 51,95 $\mathrm{kg} \mathrm{m}^{-2}$ de piso e 22,10 $\mathrm{kg} \mathrm{m}^{-3}$ de ar interno e, no inverno, 20,26kg, com $46,31 \mathrm{~kg} \mathrm{~m}^{-2}$ de piso e $19,70 \mathrm{~kg} \mathrm{~m}^{-3}$ de ar interno.

As instalações de terminação eram orientadas leste-oeste, tinham piso cimentado, telhado em duas águas com telhas de fibrocimento e pé-direito no beiral de $2 \mathrm{~m}$ na granja 1 (G1) e de 3,20m na granja 2 (G2). A G1 tinha oito baias com área de piso de $324 \mathrm{~m}^{2}$ $\left(1,62 \mathrm{~m}^{2}\right.$ animal $\left.^{-1}\right)$ separadas por tábuas de madeira, volume interno $6.325 \mathrm{~m}^{3}$, com limpeza feita diariamente pela manhã com raspagem e lavagem do piso feita uma vez na semana. No verão alojava 1.600 animais com peso médio de $75 \mathrm{~kg}$, com $46,29 \mathrm{~kg} \mathrm{~m}^{-2}$ de piso e $18,97 \mathrm{~kg}$ $\mathrm{m}^{-3}$ de ar interno e, no inverno, alojava 950 animais com peso médio de $70 \mathrm{~kg}$, com $43,21 \mathrm{~kg} \mathrm{~m}^{-2}$ de piso e $10,51 \mathrm{~kg}$ $\mathrm{m}^{-3}$ de ar interno. A G2 era formada por 49 baias com área de piso de $24,20 \mathrm{~m}^{2}\left(0,97 \mathrm{~m}^{2}\right.$ animal $\left.^{-1}\right)$, volume interno de $3.948 \mathrm{~m}^{3}$, separadas por paredes de $1,10 \mathrm{~m}$ de alvenaria, com a limpeza das baias consistindo no esgotamento da lâmina de água (com depressão de $10 \mathrm{~cm}$ no fundo das baias, cheia e com fluxo de água constante) realizada uma vez por semana. No verão, alojava 1.175 animais com peso médio de $70 \mathrm{~kg}$, perfazendo $58,49 \mathrm{~kg} \mathrm{~m}^{-2}$ de piso e $20,83 \mathrm{~kg} \mathrm{~m}^{-3} \mathrm{de}$ ar e, no inverno, alojava 950 animais com peso médio de $70 \mathrm{~kg}$, com $47,28 \mathrm{~kg} \mathrm{~m}^{-2}$ de piso e $16,84 \mathrm{~kg} \mathrm{~m}^{-3}$ de ar interno.

Medidas, análise e modelo estatístico

A concentração de $\mathrm{NH}_{3}$, a temperatura de bulbo seco (TBS) e a velocidade do ar (V) foram registradas a $1,5 \mathrm{~m}$ do piso, no nível dos animais, correspondendo a $0,95 \mathrm{~m}$ e a $1,20 \mathrm{~m}$ para creche e terminação, respectivamente, de forma a evitar que os animais danificassem os equipamentos. Os dados de TBS e V externo foram coletados no lado sul das instalações. As amostragens de poeira foram feitas a $1,5 \mathrm{~m}$ de altura do piso. Os fungos foram coletados em placas de Petri expostas nas extremidades e em pontos médios da instalação, assim como nos filtros da bomba.
Os dados de TBS e temperatura de globo negro (TGN) e a umidade relativa do ar (UR) (Monitor de Estresse Térmico 34 Quest ${ }^{\circledR}$ ), o V interno e o externo, o TBS e o UR (higrotermo-anemômetro HTA 4.200 Pacer $^{\circledR}$ ) foram registrados a cada 30 minutos, dentro e fora da instalação, durante todo o experimento. A concentração de $\mathrm{NH}$ foi registrada por amostragem completa da jornadả e no período total (Multilog, 2000 Quest $^{\circledR}$ ), em intervalos de 10 minutos. A concentração de poeira foi coletada conforme os procedimentos 0500 e 0600 do NIOSH (1994), em dias alternados no corredor central, nos horários: 08h00min, 11h00min, 14h00min e às 16h00min, usando-se uma bomba de aspiração (Gilair 5-Gilian ${ }^{\circledR}$ ), filtro de PVC de $5 \mu \mathrm{m}$ de poro e $37 \mathrm{~mm}$ de diâmetro, porta-filtros, ciclone para fração respirável e balança analítica $\left(10^{-4} \mathrm{~g}\right)$, e a vazão da bomba foi de 1,5L $\min ^{-1}$ e $1,7 \mathrm{~L}$ min $^{-1}$ e tempo de $80 \mathrm{~min}$, para poeira total e respirável, respectivamente. A identificação e a concentração de fungos foram realizadas de duas maneiras: na primeira, placas de Petri com meio completo (PONTECORVO et al., 1953) foram expostas por 15 minutos, durante três dias seguidos, e mantidas em temperatura ambiente por dois a três dias, para verificar a presença de unidades formadoras de colônias de fungos (UFC) e, na segunda, foram coletadas amostras dos filtros da bomba de aspiração.

A comparação dos ambientes de creche e terminação para a temperatura de bulbo seco (TBS) e concentração de $\mathrm{NH}_{3}$ foi realizada pelo modelo fatorial $2 \times 4 \times 2 \times 6$, representando as estações (E: verão, inverno), galpões (G: G1c, G2c, G1t e G2t, correspondente às instalações de creche e terminação das granjas 1 e 2), alturas (A: 1,5m e no nível dos animais) e horários nos intervalos (H: 7h00min às $8 \mathrm{~h} 00 \mathrm{~min}, 8 \mathrm{~h} 30 \mathrm{~min}$ às $9 \mathrm{~h} 30 \mathrm{~min}, 9 \mathrm{~h} 30 \mathrm{~min}$ às $10 \mathrm{~h} 30 \mathrm{~min}$, $11 \mathrm{~h} 30 \mathrm{~min}$ às $12 \mathrm{~h} 30 \mathrm{~min}, 14 \mathrm{~h} 30 \mathrm{~min}$ às $15 \mathrm{~h} 30 \mathrm{~min} \mathrm{e}$ $16 \mathrm{~h} 00 \mathrm{~min}$ às $17 \mathrm{~h} 00 \mathrm{~min})$, e três dias de repetições, segundo modelo estatístico pré-estabelecido.

As concentrações de poeiras e fungos foram analisadas pela estatística descritiva. As análises foram realizadas usando-se o programa estatístico SAS. As formas de condução dos processos (manejo) nas instalações, que são repetitivos e seguem um padrão, não sofreram nenhuma interferência e serviram de base para as comparações e inferências estatísticas.

\section{RESULTADOS E DISCUSSÃO}

As concentrações de poeira total e respirável no interior das instalações são mostradas na tabela 1. Verifica-se que as concentrações tiveram larga variação durante o dia e no período do ano, com valores mais altos nas instalações para creche em comparação àqueles verificados na terminação, 
Tabela 1 - Resultado da amostragem de poeira total e respirável e das condições climáticas nas instalações.

\begin{tabular}{|c|c|c|c|c|c|c|}
\hline \multirow{3}{*}{ Granja } & \multirow{3}{*}{ Fase } & & \multicolumn{4}{|c|}{ Poeira (mg.m³ $\left.{ }^{-3}\right)$} \\
\hline & & & \multicolumn{2}{|c|}{ Verão } & \multicolumn{2}{|c|}{ Inverno } \\
\hline & & & total & resp. & total & resp. \\
\hline \multirow{6}{*}{ G1 } & Creche & & $<9,16$ & $<3,67$ & $<4,17$ & $<1,47$ \\
\hline & & Concentração & $66 ; 29,1 ;$ & $<2,56$ & 65,$6 ; 21,3$ & $<0,58$ \\
\hline & & $\mathrm{UR}_{\mathrm{m}}(\%) ; \mathrm{T}_{\mathrm{m}}\left({ }^{\circ} \mathrm{C}\right) ; \mathrm{V}_{(\mathrm{m} . \mathrm{s}-1)}$ & & & & \\
\hline & Terminação & & $<3,33$ & $<0,74$ & $<3,33$ & $<0,74$ \\
\hline & & Concentração & 53,$5 ; 27,7$ & $<1,00$ & $71 ; 22$ & $<1,69$ \\
\hline & & $\mathrm{UR}_{\mathrm{m}}(\%) ; \mathrm{T}_{\mathrm{m}}\left({ }^{\circ} \mathrm{C}\right) ; \mathrm{V}_{(\mathrm{m} . \mathrm{s}-1)}$ & & & & \\
\hline \multirow{6}{*}{ G2 } & Creche & & $<4,17$ & $<0,74$ & $<4,17$ & $<2,94$ \\
\hline & & Concentração & 78,$2 ; 26,2$ & $<0,75$ & 75,$16 ; 29,8$ & $<0,83$ \\
\hline & & $\mathrm{UR}_{\mathrm{m}}(\%) ; \mathrm{T}_{\mathrm{m}}\left({ }^{\circ} \mathrm{C}\right) ; \mathrm{V}_{(\mathrm{m} . \mathrm{s}-1)}$ & & & & \\
\hline & Terminação & & $<2,50$ & $<0,74$ & $<3,34$ & $<1,47$ \\
\hline & & Concentração & 90,$2 ; 27,6$ & $<0,80$ & 92,$7 ; 15,7$ & $<1,26$ \\
\hline & & $\mathrm{UR}_{\mathrm{m}}(\%) ; \mathrm{T}_{\mathrm{m}}\left({ }^{\circ} \mathrm{C}\right) ; \mathrm{V}_{(\mathrm{m} . \mathrm{s}-1)}$ & & & & \\
\hline
\end{tabular}

resultados que estão de acordo com a literatura (SCHMIDT et al., 2002; CHANG et al., 2001 e GUINGAND, 1999). Isso ocorre devido aos fatores de densidade populacional, idade e atividade dos animais, que favorecem ao acúmulo deste particulado no ar. Além disso características construtivas das instalações e o uso mais freqüente da cortina para controle térmico ocasionam menor ventilação natural interna. Situação oposta ocorreu nas instalações para terminação que eram mais abertas, o que contribuíu para concentrações mais baixas deste particulado. As concentrações mais altas de poeira ocorreram na creche da G1, resultado que pode ser atribuído ao maior número de animais na sala e, conseqüentemente, à maior movimentação, do que às características construtivas das instalações. Essas concentrações não superaram os limites estabelecidos pelas normas NIOSH (1994) e ACGIH (2001), nem os limites propostos por DONHAM (1995). Embora a velocidade do ar tenha sido, na maior parte do tempo, próxima de zero e irregular no exterior, sendo quase nula internamente devido às barreiras existentes, a dispersão de partículas de poeira retidas nas estruturas das instalações e na cortina plástica podem ter favorecido a alta concentração, associada à movimentação dos animais, em alguns horários.

Os fungos identificados nas instalações foram Aspergillus (28\%), Neurospora (18\%), Penicillium (7\%), Colletotrichum (5\%), Fusarium (8\%) e outros (34\%). Dentro do gênero Aspergillus, foram identificados: $A$. niger, $A$. parasiticus, $A$. candidus, A. flavus, A. nidulans, A. fumigatus. A porcentagem de fungos do gênero Aspergillus identificados nos filtros de poeira respirável e de poeira total foi de 34 e $45 \%$, respectivamente, indicando que a poeira total é mais adequada para mostrar a presença desse microorganismo. Esses resultados sugerem a necessidade de maior conhecimento do ambiente microbiológico de instalações de tipologias abertas, comuns em condições tropicais.

Os resultados da análise de variância para TBS e da concentração de amônia são apresentados na tabela 2. Verifica-se que a estação do ano (E), as instalações $(\mathrm{G})$ e os horários (H) tiveram influência significativa sobre os valores de concentração de amônia e, como houve interações duplas significativas, evidencia-se uma dependência entre as variáveis e, neste caso, foi feito um desdobramento da interação, mostrado na tabela 3. Não foi constatada diferença

Tabela 2 - Resultados das análises de variância para a média horária de temperatura de bulbo seco (TBS) e concentração de amônia.

\begin{tabular}{lllc}
\hline & & \multicolumn{2}{c}{ Quadrados Médios } \\
\cline { 3 - 4 } F V & G L & TBS & $\begin{array}{c}\text { Concentração de } \\
\text { amônia }\end{array}$ \\
\hline Estação (E) & 1 & $682,1^{* *}$ & $1594,7^{* *}$ \\
Galpão (G) & 3 & $110,0^{* *}$ & 65,0 \\
Altura (A) & 1 & 0,1 & 41,0 \\
Horários (H) & 5 & $434,9^{* *}$ & $2088,3^{* *}$ \\
& & & \\
E x G & 3 & $91,4^{* *}$ & $556,7^{* *}$ \\
E x H & 5 & $14,9^{* *}$ & $475,7^{* *}$ \\
G x H & 15 & $23,4^{* *}$ & 39,7 \\
\hline
\end{tabular}

*Significativo no nível de 5\% de probabilidade.

** Significativo no nível de $1 \%$ de probabilidade.

Ciência Rural, v.37, n.2, mar-abr, 2007. 
Tabela 3 - Resultados do teste de comparação de médias para concentração de amônia $\left(\mathrm{NH}_{3}\right)$ no ambiente das instalações das granjas avaliadas.

\begin{tabular}{|c|c|c|c|c|c|c|c|c|c|c|c|c|}
\hline \multicolumn{13}{|c|}{ Concentração de amônia (ppm) } \\
\hline Horário & \multicolumn{2}{|c|}{ 7:00-8:00h } & \multicolumn{2}{|c|}{ 8:30-9:30h } & \multicolumn{2}{|c|}{ 9:30-10:30h } & \multicolumn{2}{|c|}{ 11:30-12:30h } & \multicolumn{2}{|c|}{$14: 30-15: 30 h$} & \multicolumn{2}{|c|}{$16: 00-17: 00 \mathrm{~h}$} \\
\hline Período & $\mathrm{V}$ & I & $\mathrm{V}$ & I & $\mathrm{V}$ & I & $\mathrm{V}$ & I & $\mathrm{V}$ & I & $\mathrm{V}$ & I \\
\hline Granja & \multicolumn{12}{|c|}{ Creche } \\
\hline G1 & $0,5 c^{1}$ & $7,6 \mathrm{bc}$ & $0,5 c$ & $8,1 \mathrm{bc}$ & $0,9 \mathrm{c}$ & $4,1 \mathrm{c}$ & $2,7 \mathrm{c}$ & $6,7 \mathrm{bc}$ & $7,9 \mathrm{bc}$ & 20,2ab & $12,2 \mathrm{bc}$ & $26,0 \mathrm{a}$ \\
\hline G2 & $6,4 \mathrm{bc}$ & $0,5 \mathrm{c}$ & $7,0 \mathrm{bc}$ & $0,5 c$ & $8,0 \mathrm{bc}$ & $0,9 \mathrm{c}$ & $4,0 \mathrm{c}$ & $2,9 c$ & $10,3 b c$ & $8,5 b c$ & $13,3 \mathrm{bc}$ & $14,1 \mathrm{bc}$ \\
\hline $\mathrm{T}_{\text {méd. }}\left({ }^{\circ} \mathrm{C}\right)$ & 23,0 & 19,0 & 23,5 & 19,0 & 24,5 & 23,0 & 25,0 & 24,0 & 27,0 & 26,0 & 26,5 & 24,5 \\
\hline \multirow[t]{2}{*}{$\mathrm{UR}_{\text {méd. }}(\%)$} & 92,0 & 80,0 & 90,5 & 74,0 & 88,0 & 60,0 & 81,0 & 57,0 & 72,5 & 59,0 & 75,5 & 52,0 \\
\hline & \multicolumn{12}{|c|}{ Terminação } \\
\hline G1 & $0,5 d$ & $0,5 d$ & $0,5 d$ & $0,5 d$ & $0,5 d$ & $1,2 d$ & $1,2 \mathrm{~d}$ & 7,0bcd & 7,0bcd & $20,5 a b c$ & 8,2bcd & $28,1 a$ \\
\hline G2 & $0,5 \mathrm{~d}$ & $0,5 \mathrm{~d}$ & $0,5 d$ & $0,5 d$ & $0,5 \mathrm{~d}$ & $1,2 d$ & $0,7 d$ & $5,6 \mathrm{~d}$ & $4,2 d$ & $21,5 \mathrm{ab}$ & $6,6 \mathrm{~cd}$ & $30,3 a$ \\
\hline $\mathrm{T}_{\text {méd. }}\left({ }^{\circ} \mathrm{C}\right)$ & 23,0 & 19,5 & 23,5 & 19,0 & 24,5 & 22,5 & 25,0 & 23,8 & 27,0 & 26,0 & 26,5 & 25,3 \\
\hline $\mathrm{UR}_{\text {méd. }}(\%)$ & 92,0 & 80,0 & 90,5 & 74,0 & 88,0 & 60,0 & 81,5 & 57,0 & 72,5 & 46,5 & 75,5 & 52,5 \\
\hline
\end{tabular}

${ }^{1}$ Médias seguidas por letras distintas na coluna diferem entre si pelo teste de Tukey ao nível de significância de 0,05.

V=período de verão; I=período de inverno.

significativa na concentração de $\mathrm{NH}_{3}$ para as condições de verão, mas esta foi significativa nas condições de inverno e com teores mais altos, concordando com os resultados obtidos por SCHMIDT et al. (2002), que afirmaram que as condições de clima e manejo de inverno favorecem a formação de amônia e, conseqüentemente, uma maior concentração. As figuras 1 (a, b) mostram a variação de $\mathrm{NH}_{3}$ e TBS nas instalações para creche avaliadas. Verifica-se que, para as condições de verão, os teores mais altos de $\mathrm{NH}_{3}$ foram observados na G2.

A presença de $\mathrm{NH}_{3}$ nas instalações para creche mostrou ser resultado de uma complexa interação entre vários fatores, sendo sua concentração relacionada ao volume e à circulação de ar nas instalações, o que pode explicar a maior incidência desse gás na G2 no período de verão. A concentração de $\mathrm{NH}_{3}$ também está relacionada ao manejo dos dejetos e à retirada dos substratos. A maior incidência de $\mathrm{NH}_{3}$ na G1, no período de inverno, pode ser explicada mais pelo fechamento das cortinas e pela falta de ventilação mínima do que pela lotação. Possivelmente, a densidade maior em $\mathrm{kg} \mathrm{m}^{-3}$ no verão entre as instalações e a lavagem do piso não foram suficientes para compensar o maior volume de ar contaminado na G1, mostrado pelo menor gradiente nas concentrações de $\mathrm{NH}_{3}$. Esses resultados mostram que a falta de atenção para a ventilação nas instalações de creche leva à quase ausência de ventilação mínima sanitária, propiciando teores mais altos de $\mathrm{NH}_{3}$, que estão mais relacionados ao volume e à circulação de ar no interior das instalações, ao manejo dos dejetos e da cortina, à tipologia da construção e às condições de clima local do que à lotação de suínos.

Na terminação, a tabela 2 mostra diferença significativa na concentração de $\mathrm{NH}_{3}$ nos horários, sendo maior no inverno, concordando com os resultados de SCHMIDT et al. (2002). As figuras 2 (a,b)

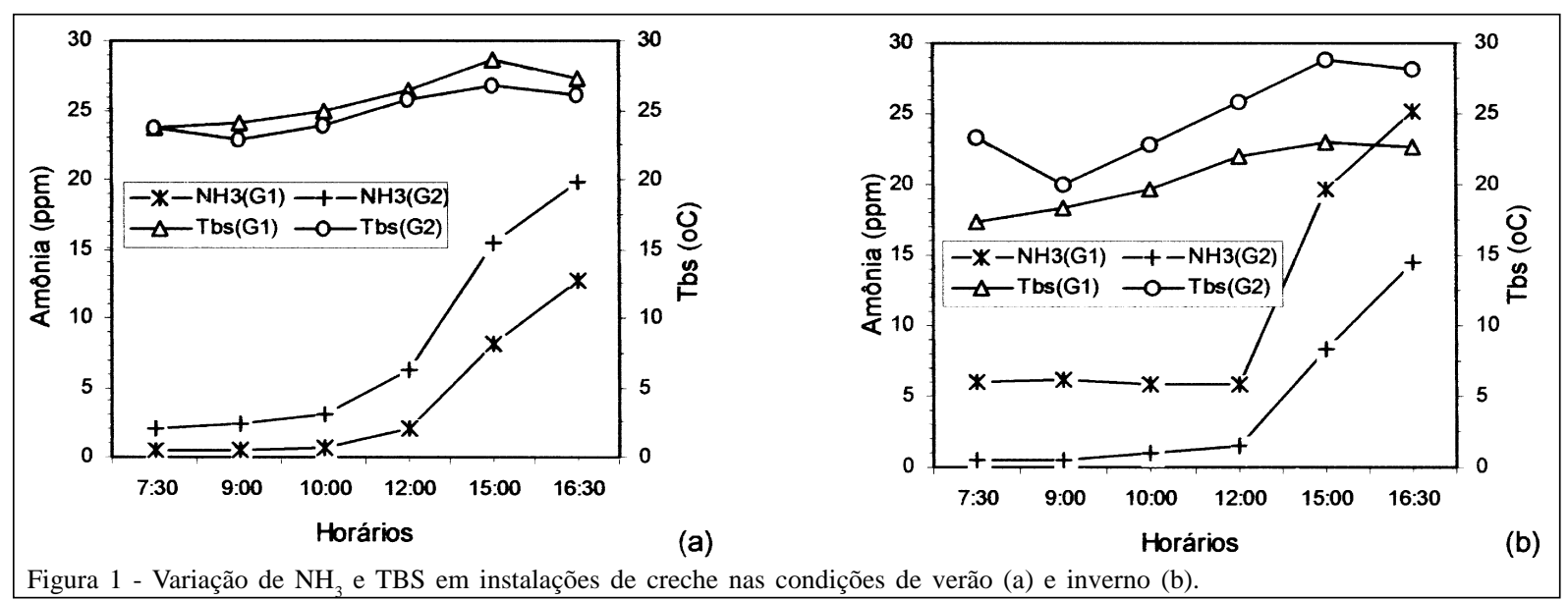

Ciência Rural, v.37, n.2, mar-abr, 2007. 

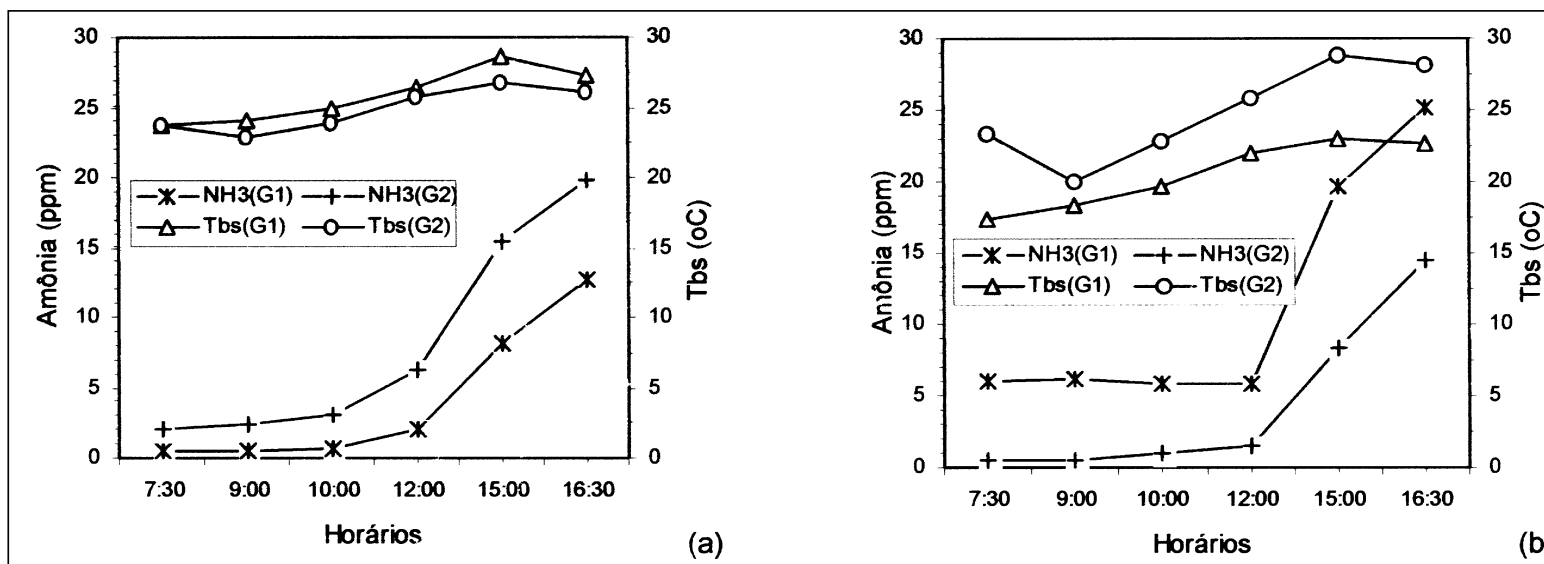

Figura 2 - Variação de $\mathrm{NH}_{3}$ e TBS em instalações de creche nas condições de verão (a) e inverno (b).

mostram a variação de $\mathrm{NH}_{3}$ e TBS nas instalações de terminação, se onde nota que os teores de $\mathrm{NH}_{3}$ no verão foram acima na G1, enquanto que, no inverno, esses teores em G1 e G2 ficaram próximos, sendo pouco superiores na G2. Semelhantemente ao descrito para amônia nas instalações de creche, a concentração está relacionada ao volume e à circulação de ar e à presença da lâmina de água. $\mathrm{O}$ intervalo maior em $\mathrm{kg} \mathrm{m}^{-3}$, no inverno, entre as instalações, com uso da lâmina de água, não foi suficiente para compensar o ambiente aéreo na G1, mostrado pela menor concentração de $\mathrm{NH}$, que variou significativamente durante o dia, concordando com os resultados obtidos por SCHMIDT et al. (2002) e CHANG et al. (2001), sendo maior à tarde, nos horários mais quentes, devido à maior atividade de fermentação de dejetos. Os teores médios de $\mathrm{NH}_{3}$ não superaram 20ppm, que afeta o desempenho dos suínos (CIGR, 1994), embora este limite tenha sido excedido em alguns horários. A mesma análise pode ser feita no aspecto de salubridade, em que o teor a partir de 20ppm começa a ser prejudicial ao trabalhador (NR-15, 1978).

\section{CONCLUSÕES}

Nas condições deste estudo, foram encontradas variações significativas nas concentrações de amônia em função do horário e do período do ano, tanto nas instalações de creche, como nas de terminação, sendo função do manejo de limpeza de dejetos e da ventilação interna. A concentração de poeira não se constitui em condição de insalubridade ao trabalhador e a presença de fungos encontrada na poeira em suspensão na creche sugere um maior controle do ambiente aéreo.

\section{REFERÊNCIAS}

AMERICAN CONFERENCE OF GOVERNMENT INDUSTRIAL HYGIENISTS - ACGIH. TLVs and BEIs Threshold limit values for chemical substances and biological exposure indices. Cincinnati, U.S., 2001. 185p.

BARKER, J. et al. Safety in swine productions systems. Waste Quality \& Waste Management. North Carolina: Cooperative Extension Service, 2002. 6p.

BRASIL. Ministério do Trabalho e Emprego. Portaria 3.214 de Jul. 1978. Normas regulamentadoras de segurança e saúde no trabalho - NR-15: Atividades e Operações Insalubres. Brasília, 1978. Acesso em nov, 2001. [on-line]. Disponível em: <http://www.mte.gov.br>.

CHANG, C.W. et al. Exposure assessment to airbone endotoxin, dust, ammonia, hydrogen sulfide and carbon dioxide in open style swine houses. Ann Occup Hyg, v.45, n.6, p.457-465, 2001.

COMMISSION INTERNATIONALE DU GÉNIE RURAL CIGR. Aerial environment in animal housing: concentrations in and emissions from farm buildings. Dublin, 1994. 116p.

DONHAM K.J. et al. Function in swine production facility workers: dose-response relationships of environmental exposures and pulmonary function. American Journal of Industrial Medicine, v.27, p.405-418, 1995.

GUINGAND, N. Dust concentrations in piggeries: influence of season, age of pigs, type of floor and feed presentation in farrowing, post-weaning and finishing rooms. In: INTERNATIONAL SYMPOSIUM ON DUST CONTROL IN ANIMAL PRODUCTION FACILITIES, 30., 1999, Proceedings... Horsens, Denmark, CIGR, 1999. p.69-75. 
JENSEN, A.O. Changing the environment in swine buildings using sulfuric acid. Transactions of the ASAE, v.45, n.1, p.223-227, 2002.

NATIONAL INSTITUTE FOR OCCUPATIONAL SAFETY AND HEALTH (NIOSH). Manual of analytical methods (NMAM). 4.ed. Cincinnati, U.S., 1994. Acesso em out, 2001. [on-line]. Disponível em: <http://www.cdc.gov/niosh/nman>
PICKRELL, J. Hazards in confinement housing - gases and dusts in confined animal houses for swine, poultry, horses and humans. Vet Hum Toxicol, v.33, n.1, p.32-39, 1991.

PONTECORVO, G. et al. The genetics of Aspergillus nidulans. Advances in Genetics, v.5, p.141-238, 1953.

SCHMIDT, D.R. et al. Continuous monitoring of ammonia, hydrogen sulfide and dust emissions from swine, dairy and poultry barns. Chicago, Illinois, U.S.: ASAE, 2002. 14p. 